\title{
The Water Yield Pattern for Annual and Monthly Scales Through a Unifying Catchment Water Balance Model
}

Dedi Liu ( $\nabla$ dediliu@163.com )

Wuhan University

Dezhi Fu

Wuhan University

\section{Research Article}

Keywords: water yield pattern, a unifying catchment water balance model, multi-time scales, land use/cover, water resources management, Global Runoff Data Centre

Posted Date: January 10th, 2022

DOI: https://doi.org/10.21203/rs.3.rs-1193877/v1

License: (c) (i) This work is licensed under a Creative Commons Attribution 4.0 International License.

Read Full License 
The water yield pattern for annual and monthly scales through a unifying catchment water balance model

Dedi Liu ${ }^{1, *}$, Dezhi Fu ${ }^{1}$

${ }^{a}$ State Key Laboratory of Water Resources and Hydropower Engineering

Science, Wuhan University, Wuhan 430072, China

*Correspondence to

Dr. Dedi Liu

State Key Laboratory of Water Resources and Hydropower

Engineering Science

Wuhan University, Wuhan 430072 China

E-mail: dediliu@whu.edu.cn 


\section{$1 \quad$ Abstract}

2 Long-term scheduling and short-term decision-making for water resources

3 management often require understanding the relationship of water yield pattern

4 between the annual and monthly scales. As the water yield pattern mainly depends on

5 land cover/use and climate, a unifying catchment water balance model with factors

6 has been adopted to derive a theoretical water yield pattern with annual and monthly

7 scales. Two critical values at the parameters $\varepsilon=1-\sqrt{2} / 2$ and $\phi=1.0$ are identified. The

8 parameter $\varepsilon$ referring to the water storage (land use/cover) and evaporation (climate)

9 changes can make more contribution than $\phi$ for water yield when $\phi>1.0$, especially

with $\varepsilon<1-\sqrt{2} / 2$. But there is less contribution made by $\varepsilon$ when $\phi<1.0$. The derived

11 theoretical water yield patterns have also been validated by the observed data or the simulated data through the hydrological model. Due to the bias of the soil moisture data, a lot of the estimated parameter $\varepsilon$ values are over its theoretical range, especially for the monthly scale in humid basins. The performance of the derived theoretical water yield pattern at annual scale is much better than that at monthly scale while there are only a few data sets from the arid basin at every months fall within their theoretical ranges. Even the relative contributions of $\varepsilon$ is found to be bigger than those of $\phi$ due to $\varepsilon<1-\sqrt{2} / 2$ and $\phi>1.0$, there are no significant linear relationships between annual and monthly parameters $\varepsilon$ and $\phi$. Our results not only validate the derived theoretical water yield pattern with the estimated parameter directly by the observed or simulated data rather than the calibrated parameter, but also can guide for further understanding physical of water balance to conversion time scales for the combing 
long-term and short-term water resources management.

24 Key words: water yield pattern; a unifying catchment water balance model; multi-

25 time scales; land use/cover; water resources management; Global Runoff Data Centre 


\section{Introduction}

Water yield pattern mainly depends on land cover/use and climate (Legesse et al., 2003, Zahabiyoun et al., 2013; Kirby et al., 2016; Belay and Mengistu, 2019; Gusarov, 2020). Numerous studies through the paired-watershed experiment method (Bosch and Hewlett, 1982; Zhang et al., 2003; Brown et al., 2005; Monteith et al., 2006) or especially the hydrological model (Nyatuame et al., 2020; Hu et al., 2020) have been done to figure out the effects of land cover/use and climate on water yield pattern. However, there is highly variable and inconsistent results of the effects of the changes from land use/cover and climate on the water yield pattern (e.g. limited effects (Buttle, et al., 2000; Galleguillos et al., 2021), no effects (Antonio, et al., 2008), or positive effects (Wang et al., 2011; Getachew, et al., 2021)), which have led to debates in water resources management communities (Andréassian et al., 2004), especially the results at different time scales in a place can bring confusing. Land cover/use varies with the interaction between the geology, soils, vegetation and meteorological factors (e.g. precipitation, evaporation) while fluxes of energy and water are always complex with nonstationary properties (Wood, 1995). As the fluxes have different time scales, their interactions at the different scales emerge as the time-scales effects for hydrological simulation (Sivapalan 2006; Foster et al., 2021). Understanding the interaction between scales not only parameterize longer time scale model from shorter time scale (and vice versa) for improving the transfer ability of hydrological model but also help figure out the dominant factors of water yield pattern for long-term scheduling and short-term decision-making of water resources management. Therefore, a unifying 
method for different time scales that describes the contribution or influence of climate and land cove/ use on water yield can improve the understanding on this interaction across time scales.

Due to the controlling factors on rainfall-runoff process varying with temporal scale, identifying the water balance behavior over various temporal scales remains a challenging research task (Zhang, et al., 2008; Vinogradov et al., 2011; Wang and Tang, 2014; Ning et al., 2019). Various hydrologic models have been independently developed at annual and monthly scales for capturing the dominant factors on their processes (Beven and Moore, 1993; Blöschl and Sivapalan, 1995; Beven, 1998; Dutta et al., 2000; Beven, 2004). For instance, Budyko-type models at the annual scale and the "abcd" model at the monthly scale. And the longer water balance is cumulated by shorter ones. There should be a common organizing principle that link between the longer and shorter water balance. Wang et al. (2015) had discovered a possible link between the Maximum Entropy Production (MEP) principle and annual Budyko-type model and inter-annual L'vovich-type formulation (L'vovich, 1979). Based on the MEP principle and the proportionality hypothesis proved by Wang and Tang (2014), Zhao et al. (2016) had derived a unifying catchment water balance model for connecting the long term scale Budyke-type mode and monthly "abcd" model. The validity of the unifying catchment water balance model has been demonstrated in a lot of catchments in contiguous United States (Zhang ${ }^{\mathrm{a}}$, et al., 2020; Zhang ${ }^{\mathrm{b}}$, et al., 2020; Deng and Wang, 2021). However, these validation or verification studies have been done by calibrating of the unifying water balance model in United States. If the 
parameters of the unifying water balance model are directly estimated by the observed data or the data resulted from hydrologic model with a specific time scale, the application of the unifying model, especially in ungauged basin, will be extended and the water yield pattern depended on the parameters of the unifying water balance model will guide for further improvements and understanding physical of water balance.

The water yield pattern has been theoretically recognized as depending on the ratio of precipitation on wetness and on the watershed characteristics through Fuh's equation. Its global pattern has been comprehensively analyzed using a global data set and the possible mechanisms have been explained through the ratio of precipitation on wetness and the watershed characteristics (Zhou, et al., 2015). However, there have only been studies from the annual scale aspect. In this study, a theoretical water yield pattern based on the unifying catchment water balance model for the annual and monthly scales, is analyzed and validated using the global publishing data set.

The aim of this paper is therefore: (1) to derive theoretical water yield pattern for annual and monthly time scales based on a unifying catchment water balance model, and (2) to validate the water yield pattern directly through the observed data or the data resulted from hydrologic model with a specific time scale rather than the calibrated parameters, and (3) to quantify the relative contributions of factors to the water yield pattern. Therefore, in the remainder of the paper, the theoretical deviation of water yield pattern is shown in the methodology section. Study area and global data for validating the water yield pattern are described in the third section. The global 
water yield pattern and its validation are presented and discussed in the fourth section. Finally, conclusions and discussion on possible research forward are stated in the fifth section.

\section{Methodology}

\subsection{A unifying catchment water balance model for monthly and annual time} scales

Application of the optimal principle of maximum entropy production, a unifying catchment water balance model has been derived to draw connections between the widely used water balance models at different time scales, i.e. the long time scale (annual is taken as long time scale in this study) Budyko-type model and the monthly "abcd" model (Zhao et al., 2016).

$$
\frac{R}{P}=1-\frac{1+\frac{E_{P}+\Delta W_{P}}{P}-\sqrt{\left(1+\frac{E_{P}+\Delta W_{P}}{P}\right)^{2}-4 \varepsilon(2-\varepsilon) \frac{E_{P}+\Delta W_{P}}{P}}}{2 \varepsilon(2-\varepsilon)}
$$

where $\varepsilon=\frac{\Delta W_{0}+E_{0}}{\Delta W+E}, \Delta W$ is the water storage change held in soil and vegetation $(\mathrm{mm})$; $\Delta W_{p}$ is the storage capacity change $(\mathrm{mm}) ; \Delta W_{0}$ is the initial water storage change (mm). Evapotranspiration to air $(E, \mathrm{~mm})$ is subdivided into initial evapotranspiration $\left(E_{0}, \mathrm{~mm}\right)$ and continuing evapotranspiration $\left(E_{c}, \mathrm{~mm}\right) ; E_{p}$ is the potential evapotranspiration $(\mathrm{mm}) ; P$ is precipitation $(\mathrm{mm}), R$ is the runoff depth to river (is also taken as the water yield, mm). If the $\left(E_{p}+\Delta W_{p}\right) / P=\phi$, the equation (1) can be transformed as: 


$$
\frac{R}{P}=1-\frac{1+\phi-\sqrt{(1+\phi)^{2}-4 \varepsilon(2-\varepsilon) \phi}}{2 \varepsilon(2-\varepsilon)}
$$

If letting $a=\varepsilon(2-\varepsilon)$ and $b=E_{p}+\Delta W_{p}$, the equation (1) is the identical to the monthly “abcd" water balance mode (Thomas, 1981; Zhao et al., 2016). At the annual scale, if the storage changes are assumed to be neglectable, the $\varepsilon=E_{0} / E$ and the equation (1) can be transformed into

$$
\frac{R}{P}=1-\frac{1+\frac{E_{P}}{P}-\sqrt{\left(1+\frac{E_{P}}{P}\right)^{2}-4 \varepsilon(2-\varepsilon) \frac{E_{P}}{P}}}{2 \varepsilon(2-\varepsilon)}
$$

And the equation (3) is an equivalent form of the Budyko-type model (Wang et al., 2015). The $R / P$ is a dimensionless annual or monthly water yield coefficient; $\phi=\left(E_{p}+\Delta W_{p}\right) / P$ is a dimensionless variable, which means the relative potential loss comparing to the precipitation. $\varepsilon$ is a constant parameter that is dependent on the ratios of $\Delta W_{0} / \Delta W\left(\lambda_{1}\right)$ and $E_{0} / E\left(\lambda_{2}\right)$, and $\min \left\{\lambda_{1}, \lambda_{2}\right\} \leq \varepsilon \leq \max \left\{\lambda_{1}, \lambda_{2}\right\} . \lambda_{1}, \lambda_{2}$ are the parameters standing for the marginal contribution of input resource $P$ into $\Delta W$ and $E$ in a catchment, respectively. The initial evaporation $\left(E_{0}\right)$ is from direct evaporation occurring due to vegetation interception and water storage in top soils (Wang and Yang, 2014), the value of $\varepsilon$ represents watershed characteristic including land cover and land use. One extreme case occurs when $\varepsilon=1.0, R / P=0\left(E_{p} \geq P\right)$ or $R / P=1-\left(E_{p} / P\right)$ $\left(E_{p}<P\right)$ where all precipitation remains in watershed for the initial evaporation $\left(E_{0}\right)$ and the initial soil storage changes $\left(\Delta W_{0}\right)$. The opposite extreme case occurs when $\varepsilon$ is approaching $0, R / P=1 /\left(1+E_{p} / P\right)$. The relationships between the ratio $R / P$ and the factor $\phi$ with different $\varepsilon$ are shown in Figure 1. The range of the relationship are defined by the boundaries of $\varepsilon=1.0,\left(R / P=0, E_{p} \geq P\right.$ or $\left.R / P=1-\phi, E_{p}<P\right)$ and $\varepsilon=0,(R / P=1 /(1+\phi))$. 
The contributions of $\phi$ to the $R / P$ are different with the different $\varepsilon$ values. As the factors $\phi$ and $\varepsilon$ are dominated by different factors at different time scales, such as the climate factor $E_{p}$ for long time period, and the watershed characteristics $W_{p}$ for short time period, the effects of the climate and watershed characteristics on the ratio $R / P$ varied with the time scales.

\subsection{Derivation of the water yield patterns}

The efficient index of water yield can be described by the ratio of $R / P$. The water yields patterns can be derived from the sensitivity functions of $R / P$ to $\phi$ and $\varepsilon$ in the unifying catchment water balance model as shown in the equation (2).

$$
\begin{aligned}
& \frac{\partial \frac{R}{P}}{\partial \phi}=\frac{-1}{2 \varepsilon(2-\varepsilon)}\left[1-\frac{(1+\phi)-2 \varepsilon(2-\varepsilon)}{\sqrt{(1+\phi)^{2}-4 \varepsilon(2-\varepsilon) \phi}}\right] \\
& \frac{\partial \frac{R}{P}}{\partial \varepsilon}=\frac{\left(1+\phi-\sqrt{(1+\phi)^{2}-4 \varepsilon(2-\varepsilon) \phi}\right)-\frac{\phi 2 \varepsilon(2-\varepsilon)}{\sqrt{(1+\phi)^{2}-4 \varepsilon(2-\varepsilon) \phi}}(1-\varepsilon)}{\varepsilon^{2}(2-\varepsilon)^{2}}
\end{aligned}
$$

The equations (4) - (5) can be described as Figure 2. $R / P$ decreases with $\phi$ for all $\varepsilon(0$, 1] shown in Figure 1 and Figure 2(a) where all the $\partial(R / P) / \partial \phi$ are negative.

There are two type patterns of $\partial(R / P) / \partial \phi$ in figure $2(a)$ : one is the only convex parabolic curve, the other one is " $\mathrm{S}$ " shape curve. As the second derivative of the equation (4) equals to $-6(1-\varepsilon)^{2} \frac{\phi+2(\varepsilon-1)^{2}-1}{\left[(1+\phi)^{2}-4 \varepsilon(2-\varepsilon) \phi\right]^{5 / 2}}$, a mathematical theorem guarantees the convex parabolic curve when $\phi>-2(1-\varepsilon)^{2}+1.0$, and $\varepsilon \leq 1-\sqrt{2} / 2$ can be obtained for $\phi \leq 1$. When $\varepsilon=1-\sqrt{2} / 2$, the equation (1) is the same as Fu's equation with 
the parameter $\omega=2$ (Wang and Tang, 2014; Fu, 1981). When $\varepsilon \geq 1-\sqrt{2} / 2$, it can be found that the "S" shape curve in Figure 2(a). All value of $\partial(R / P) / \partial \varepsilon$ in Figure 2(b) are below 0 for all $\phi(0, \infty)$, showing that the $R / P$ is decreasing with $\varepsilon$. The second derivatives of the equation (5) with $\phi$, all curves in Figure 2(b) are the convex parabolic, showing that the value of $\partial(R / P) / \partial \varepsilon$ are decreasing as $\phi<1$ while increasing as $\phi>1$. Therefore, $\varepsilon=1-\sqrt{2} / 2$ and $\phi=1$ are the two critical values for identifying water yield patterns.

\subsection{The relative contributions of $\phi$ and $\varepsilon$}

On the basis of equations (4) and (5), the relative contributions of $\phi\left(R C_{\phi}\right)$ and $\varepsilon$ $\left(R C_{\varepsilon}=1-R C_{\phi}\right)$ are calculated according to:

$$
R C_{\phi}=\frac{\left|\frac{\partial \frac{R}{P} \mid}{\partial \phi}\right|}{\left|\frac{\partial \frac{R}{P} \mid}{\partial \phi}\right|+\left|\frac{\partial \frac{R}{P}}{\partial \varepsilon}\right|} \times 100 \%
$$

When $\phi$ is less 1.0 and is approaching to 0 , the $R C_{\phi}$ is bigger than $50 \%$, showing that the $\phi$ is the dominate factor for the water yield coefficient. And higher $\varepsilon$ value, more contribution by $\phi$. Otherwise, the dominate factor is $\varepsilon$ when $\phi>1$. And the higher $\varepsilon$ value, less contribution by $\phi$. As shown in Figure 3, there is " $\mathrm{S}$ " shape curve when $\varepsilon>1-\sqrt{2} / 2$ while the curves are concave for all $\phi(0, \infty)$ when $\varepsilon \leq 1-\sqrt{2} / 2$. Different from the definition of the changes of $R / P$ due to the changes in $\phi$ and $\varepsilon$ (Gudmundsson, et al., 2017), the relative contributions of $\phi$ and $\varepsilon$ defined by equation (6) can compare 
the relative magnitudes of the sensitivity of $\phi$ and $\varepsilon$ to the sensitivities of $R / P$ that is critical for the water yield pattern (Zhou et al., 2015; Zhou et al., 2018).

All the equations (4)-(6) are derived from the unifying catchment water balance model, the results of water yield pattern and the relative contributions of factors in section 2.2 and 2.3 can be applied in both monthly and annual scales. Both the parameters $\varepsilon$ and $\phi$ are refereeing the $E, P$ and $W$ that can be defined as climate and land cover/land use, watershed characteristics, so the effects of the climate and land cover/land use, watershed characteristics on water yield are dominated by the $\varepsilon$ and $\phi$ values at the monthly and annual scales.

\section{Data Description}

The data used in this study were obtained from two sources: Grid data and outputs from the hydrologic model. As the information on vegetation type and historical data is incomplete, only 1467 catchments around the world from 1980 to 2009 were picked out according to their detailed precipitation, runoff, potential evaporation, land cover/land use and the soil water storages outputted from the hydrological model at both monthly and annual scales.

The annual and monthly runoff data runoff data at the 1467 gauge stations were obtained from the Global Runoff Data Centre (GRDC, available from the website at https://www.compositerunoff.sr.unh.edu/html/Data/index.html.). $\quad$ Month-by-month variations in potential evapotranspiration with the period 1980-2009 are obtained from the latest version at $0.5^{\circ} \times 0.5^{\circ}$ resolution and produced by Climatic Research 
Unit (CRU) at the University of East Anglia with Time-series (TS) data version 4.03 (University of East Anglia Climatic Research Unit; Harris, 2020). The monthly data are calculated from daily or sub-daily data by National Meteorological Services and other external agents. Although the soil moisture data might be determined by the remote sensing observations including soil moisture information from the L-band Soil Moisture and Ocean Salinity (SMOS) and Soil Moisture Active Passive (SMAP) mission, and Terrestrial water storage information from the Gravity Recovery And Climate Experiment (GRACE), these data play a disproportionately large role in the water cycle (Mc Coll et al., 2017). Soil moisture resulted from a hydrological model is taken as references for understanding hydrological process. A grid-based global hydrologic model- PCR-GLOBWB, developed by the Department of Physical Geography, Utrecht University, the Netherlands (Sutanudjaja, et al., 2018), has been driven by CRU TS data and validated by GRDC data, and its soil moisture results (available from the website at http://wci.earth2observe.eu/portal/) were used for estimating the soil storage changes.

Due to substantially fewer gauge stations used in CRU TS series of data sets, Gridded monthly precipitation from 2000 to 2009 was obtained from the Global Precipitation Climatology Centre (GPCC, https://dwd.de/EN/ourservices/gpcc/gpcc.html) in this study, which was estimated from global station data (Schneider et al 2011, https://esrl.noaa.gov/psd/data/gridded/data.gpcc.html). Its spatial resolution is $0.25^{\circ} \times 0.25^{\circ}$. And the annual precipitation was calculated from the monthly precipitation. 
Land cover type in each $0.05^{\circ}$ pixel in 2009 is derived from the Terra and Aqua combined Moderate Resolution Imaging Spectroradiometer (MODIS) Land Cover $\begin{array}{lllllll}\text { Climate } & \text { Modeling } & \text { Grid } & \text { (CMG) } & \text { (MCD12C1) } & \text { Version } & 6\end{array}$ (https://doi.org/10.5067/MODIS/MCD12Q1.006). There are 11 natural vegetation classes, three human-altered classes and three non-vegetated classes in this MODIS Terra+Aqua Combined Land Cover product. If a class of them occupies more than $90 \%$ of total area for a basin, the basin is defined as the classes of land cover; otherwise, the basin is defined as a mixture basin. And then six classes land cover and basins have been defined as shown in Figure 4. These data are available at the website https://search.earthdata.nasa.gov.

\section{Results and discussion}

\subsection{Performance and validation of the water yield patterns at annual scales}

All the data set estimated by the observed or simulated data from PCR-GLOBWB hydrologic model at the annual scales shows that more than 90 percent of them fall within the theoretical range. Most of them fall in the range with $R / P \leq 0.8$ and $0.5 \leq \phi \leq 1.5$ and there seems to be a linear relationship between $R / P$ and $\phi$ (shown in Figure 5). If the $\varepsilon$ value of every land cover class was calibrated by the obtained data set (listed in Table 1) with the minimization of Root Mean Square Error (RMSE) of flow, its value of forest $(\varepsilon=0.324)$ is the minimum while the $\varepsilon$ value of grassland is the maximum one ( $\varepsilon=0.543)$ among them. The differences between forest cover and any one of the other five land covers $\Delta R / P$ change with $\phi$ as unimodal curves with their 
peak values at the $\phi$ values of 1.0, which fall within the theoretical $\varepsilon$ range. All the calibrated values of $\varepsilon$ are bigger than $1-\sqrt{2} / 2$, there are the " $\mathrm{S}$ " shape curves of the distribution of the sensitivity functions $R / P$ to $\phi$. And there is less contribution by $\phi$ (Shown in Fig. 6(a)) while the contribution by $\varepsilon$ is higher in the most of selected areas (shown in Fig. 6(b)).

\subsection{Performance and validation of the water yield patterns at monthly scales}

The water yield patterns at monthly time scale are shown in Figure 7. There are lots of data estimated by observed and simulated data from hydrologic model fall without the theoretical range with $0 \leq \varepsilon \leq 1$. And more data from the period of October to May fall without the theoretical range comparing that from June to October. Most of them are fall within the range that $\varepsilon<0$. The data from different land cover fall within the theoretical range are also shown in the Figure 8(a). All types of land cover show better performance (falling within the theoretical range) during the period from June to October, especially the cropland while the performance from the grassland is no significant different within different months (i.e. a year). When the value of $\varepsilon$ is less than 0 in a basin (without the theoretical range), it can be deduced that its corresponding $R / P$ is bigger than $(E+\Delta W) /\left(E_{p}+\Delta W_{p}\right)$. The data set that fall within the range $\varepsilon>1$ in every month can be found when $R>P$ due to the human activities such as reservoir operation. The aridity index, defined as the ratio of annual potential evapotranspiration to precipitation, has been widely used for dividing climatic zones (McVicar et al., 2012), 596 humid, 604 semi-arid and 267 arid climate basins have 
been classified, respectively. The percentages of basins fall within the theoretical range as shown in Figure 8(b). The basins from the arid zone are stable and most of them fall within the theoretical range while the basins from the humid zone are variable and only the data set of them from June to October are over $50 \%$.

According to the unifying catchment water balance model, its form at monthly scale is the "abcd" model. However, monthly performances by the observed or simulated data as shown in section 3 cannot fall within their theoretical ranges while the annual data data from the humid zone. The parameters $\phi$ and $\varepsilon$ of unifying catchment water annual time scale while poor at monthly scale globally. 
In order to compare the water yield patterns at annual and monthly scales based on the unifying catchment water balance model, the basins with the data falling within the theoretical range for every 12 month are selected. 169 basins are picked out from the 1467 ones as shown in Figure 9. Most of the data set from these basins falls within the range of $\varepsilon<1-\sqrt{2} / 2$ and $\phi>1$. As shown in Figure 10, the value of $R / P$ at annual scales is lower than their values at month scales. The change of $R / P$ is more sensitive to the parameter $\varepsilon$ rather than the parameter $\phi$. The annual and monthly values of $\phi$ and $\varepsilon$ in these selected 169 basins are shown in Figure 11. It can be found that the annual regionalization are higher. Even there are several months (e.g. May, Jun, July and August) with small variations as the annual scale, a lot of outliers can be found in these months. slightly lower than those at monthly time scale. As the $R C_{\phi}=1-R C_{\varepsilon}$ from the equation

301 (6), there is an opposite relationship between annual and monthly relative 
contributions of $\phi$ for the $R / P\left(R C_{\phi}\right)$.

The relationships of the estimated parameters $\phi$ and $\varepsilon$ between their annual and monthly time scales are shown in Figure $13\left(a_{1}\right)$ and $\left(a_{2}\right)$. It can be easily found that almost all the $\phi$ value at every monthly scale is significantly bigger than those at annual time scale. Their relationships are nonlinear relationship, especially in Nov, Dec, Jan and Feb. More than half points are distributed under the 1:1 regression linear, which indicates the annual $\varepsilon$ value is bigger than those at monthly scales. Due to the impact factors of $\phi$ or $\varepsilon$ at annual and monthly are different, especially the water storage change held in soil and vegetation, single variable linear regression model does not support to the their conversion. More variables should be taken in the conversion of annual scale and monthly scale model. The relationships between the sensitivities of $R / P$ to $\phi$ or $\varepsilon$ at annual and monthly scale are shown in Figure $13\left(\mathrm{~b}_{1}\right)$ and $\left(\mathrm{b}_{2}\right)$. According the Figure 2, all the sensitivities of $R / P$ to $\phi$ or $\varepsilon$ are negative. However, the relationships between their sensitive values at annual and monthly scales are positive regression as those for $\phi$ or $\boldsymbol{\varepsilon}$ values shown in Figure13 $\left(\mathrm{a}_{1}\right)$ and $\left(\mathrm{a}_{2}\right)$. Both the values of $\partial(R / P) / \partial \phi$ and the values of $\partial(R / P) / \partial \varepsilon$ at the annual scale are bigger than those at every monthly scale (above the 1:1 line shown in Figure 13 $\left(b_{1}\right)$ and Figure $\left.13\left(b_{2}\right)\right)$. Most of $\partial(R / P) / \partial \phi$ values are from -0.1 to 0 for both annual and monthly scales while the values of $\partial(R / P) / \partial \varepsilon$ distributed more evenly from -0.5 to 0 . As the sensitivity value of $R / P$ to the parameter can help the uncertainty analysis and the improvement the performance of the model, the bigger value indicate these two parameters $(\phi$ and $\varepsilon$ ) are more important for annual scale, especially the model 
structures are the same for these two time scales. According to the distribution of the points shown in Figure $13\left(b_{2}\right)$, the parameter $\varepsilon$ can make higher contribution in different conditions as the $R C_{\varepsilon}$ value shown in Figure 12.

\section{Conclusion}

Water yield pattern at different time scales is impacted by different factors. The parameters of the unifying catchment water balance model can reflect the impacts due to same model structure at annual and monthly scales. The unifying catchment water balance model has been employed to figure out that the parameters $\varepsilon=1-\sqrt{2} / 2$ and $\phi=1$ are the two critical values for water yield patterns at the two time scales.

At long-term (i.e. annual) scale, the performance of the unifying catchment water balance model is much better than that at short-term (i.e. monthly) due to the rationality of negligible soil water storage change at annual scale. However, there are non-negligible components at monthly scale such as the soil water storage change and evapotranspiration that are difficult to be observed directly in basin scale. The simulation values of these components had also not been directly validated under the discharge performance evaluation. The linear relationship assumption in the unifying catchment water balance model can be hardly satisfied at short-term. Therefore, it is not surprise that a lot of data set fall without the theoretical range, especially from the humid basin with significant soil storage fluctuation at monthly scale. Our results can also open up new requirement for studying how to completely validate the performance of hydrological model (not only the discharge). 
The sensitivities of $R / P$ to $\phi$ or $\varepsilon$ at annual scale are higher than those at monthly scale. The relative contributions of $\varepsilon$ for the water yield pattern is more than those of $\phi$. Due to the impact factors of $\phi$ or $\varepsilon$ at annual and monthly are different, the conversion of the parameters of $\phi$ or $\varepsilon$ from annual to monthly or from monthly to annual should be assumed to be nonlinear or multivariable model.

Even the unifying catchment water balance model through the maximum entropy production principle can derive the annual, monthly and event scales, its application at event scale have not be validated in this study due to the shortages of observed or simulated data for water balances. There are more works to be done for figuring out the water yield patterns between different scales; however, our study has made model at annual and monthly scales.

The author gratefully acknowledges the financial support from the National Natural Science Foundation of China (Nos. 51879194 and 51579183). This work is also partly funded by the Ministry of Foreign Affairs of Denmark and administered by Danida

\section{Declaration of Interest Statement}

367 The authors declare they have no conflicts of interest to this work. 


\section{Data Availability Statement}

The data that support the findings of this study are available from the website mentioned in the paper or through contacting the corresponding author.

\section{References}

Andréassian, V., 2004. Waters and forests: from historical controversy to scientific debate. J. Hydrol. 291, 1-27.

Antonio, C. B., Enrique, M. T., Miguel, A. L. U. \& Jose, M. L. P., 2008. Water resources and environmental change in a Mediterranean environment: the south-west sector of the Duero river basin (Spain). J. Hydrol. 351, 126-138.

Belay, T., Mengistu, D.A., 2019. Land use and land cover dynamics and drivers in the Muga watershed, Upper Blue Nile basin, Ethiopia. Rem. Sens. Appl. Soc. Environ. 15100249.

Beven, K.J., Moore, I.D.(Eds.), 1993. Terrain Analysis and Distributed Modelling in Hydrology (Advances in Hydrological Processes), Wiley (1993), p.256.

Beven, K.J., 2004. Rainfall Runoff Modelling: The Primer Wiley (2004). 372pp.

Beven. K.J. Ed., 1998. Distributed Hydrological Modelling: applications of the Topmodel Concept (Advances in Hydrological Processes). Wiley (1998)356pp.

Blöschl, G., Sivapalan, M., 1995. Scale issues in hydrological modelling: A review, Hydrol. Process., 9, 251-290, doi:10.1002/hyp.3360090305.

Bosch, J.M., Hewlett, J.D., 1982. A review of catchment experiment to determine the effect of vegetation changes on water yield and evapotranspiration. J. Hydrol. 55, 3-23.

Brown, A.E., Zhang, L., McMahon, T.A., Western, A.W., Vertessy, R.A., 2005. A review of paired catchment studies for determining changes in water yield resulting of alterations in vegetation. 
Buttle, J. M. and Metcalfe, R. A., 2000. Boreal forest disturbance and streamflow response, northeastern Ontario. Can. J. Fish. Aquat. Sci. 57, 5-18.

Deng, C., Wang, W.G., 2021. A two-stage partitioning monthly model and assessment of its performance on runoff modeling. J. Hydrol. 592, 125829.

Dutta, D., Herath, S., Misake. K., 2000. Flood inundation simulation in a river basin using a physically based distributed hydrologic model. Hydrol. Process., 14, 497-519.

Foster, A., Trautz, A.C., Bolster, D., Illangasekare, T., Singha, K., 2021. Effects of large-scale heterogeneity and temporally varying hydrologic processes on estimating immobile pore space: A mesoscale-laboratory experimental and numerical modeling investigation. J. Contam. Hydrol. 241, 103811.

Fu, B.P., 1981. One the calculation of the evaporation from land surface [in Chinese]. Sci. Atmos. Sin., 5(1), 23-31.

Getachew, B., Manjunatha, B.R., Gangadhara Bhat, H. 2021. Modeling projected impacts of climate and land use/land cover changes on hydrological responses in the Lake Tana Basin, upper Blue Nile River Basin, Ethiopia. Journal of hydrology. 595, 125974.

Gudmundsson, L., Greve, P., Seneviratne, S., 2017. Correspondence: Flawed assumptions $\begin{array}{lllll}\text { compromise water yield assessment. Nat Commun. } & 14795 .\end{array}$ https://doi.org/10.1038/ncomms14795

Gusarov, A.V., 2020. The response of water flow, suspended sediment yield and erosion intensity to contemporary long-term changes in climate and land use/cover in river basins of the Middle Volga Region, European Russia. Sci. Total Environ. 719, 6, 134770. 
Hu, Y.F., Gao, M., Batunacun., 2020. Evaluations of water yield and soil erosion in the ShaanxiGansu Loess Plateau under different land use and climate change scenarios. Environ. Dev. 34, 100488

Kirby, J., Mainuddin, M., Mpelasoka, F., Ahmad, M.D., Palash, W., Quadir, M.E., ShahNewaz, S.M., Hossain, M.M., 2016. The impact of climate change on regional water balances in Bangladesh. Clim. Change 135, 481-491. https://doi.org/10.1007/s10584-016-1597-1.

L’vovich, M. I., 1979. World Water Resources and Their Future, 415 pp., AGU, Washington, D. C.

Legesse, D., Vallet-Coulomb, C., Gasse. F., 2003. Hydrological response of a catchment to climate and land use changes in Tropical Africa: case study south central Ethiopia. J. Hydrol., 275, 67-85, 10.1016/S0022-1694(03)00019-2.

McColl, K. A., Alemohammad, S. H., Akbar, R., Konings, A. G., Yueh, S., Entekhabi, D., 2017. The global distribution and dynamics of surface soil moisture. Nat. Geosci. 10(2), 100-104. https://doi.org/10.1038/ngeo2868.

McVicar, T.R., Roderick, M.L., Donohue, R.J., Van NIEL, T.G., 2012. Less bluster ahead ? Ecohydrological implications of global trends of terrestrial near-surface wind speeds. Ecohydrol. 5(4), 381-388.

Monteith, S. S., Buttle, J. M., Hazlett, P. W., Beall, F. D., Semkin, R. G., Jeffries, D. S., 2006. Paired-basin comparison of hydrologic response in harvested and undisturbed hardwood forests during snowmelt in central Ontario: II. Streamflow sources and groundwater residence times. Hydrol. Process. 20, 1117-1136

Ning,T.T., Zhou, S. Chang, F.Y., Shen, H., Li, Z., Liu, W.Z., 2019. Interaction of vegetation, climate and topography on evapotranspiration modelling at different time scales within the 
Nyatuame M , Amekudzi L K, Agodzo S K., 2020. Assessing the land use/land cover and climate change impact on water balance on Tordzie watershed. Remote Sensing Applications: Society and Environment:100381.

Schneider, U., Becker, A., Finger, P., Meyer-Christoffer, A., Rudolf, B., Ziese, M., 2011. GPCC monitoring product: Near real-time monthly land-surface precipitation from rain-gauges based on SYNOP and CLIMAT data. Accessed 6 April 2012, doi:10.5676/DWD_GPCC/MP_M_V4_100.

Sivapalan, M., 2006. Pattern, Process and Function: Elements of a Unified Theory of Hydrology at the Catchment Scale. John Wiley \& Sons, Ltd, 2006.

Sutanudjaja, E.H., van Beek, R., Wanders, N., et al., 2018. PCR-GLOBWA 2: a 5 arc-minute global hydrological and water resources model. Geosci. Model Dev. Discuss., 11(6), 24292453. https://doi.org/10.5194/gmd-11-2429-2018.

Thomas, H. A., 1981. Improved methods for national water assessment, water resource contract WR15249270, USGS unnumbered series, final report, Harvard Water Resour. Group. [Available at http://pubs.er.usgs.gov/publication/70046351.]

University of East Anglia Climatic Research Unit; Harris, I.C.; Jones, P.D. (2020): CRU TS4.03: Climatic Research Unit (CRU) Time-Series (TS) version 4.03 of high-resolution gridded data of month-by-month variation in climate (Jan. 1901- Dec. 2018). Centre for Environmental $\begin{array}{llll}\text { Data } & \text { Analysis, } & 22 & \text { January }\end{array}$ http://dx.doi.org/10.5285/10d3e3640f004c578403419aac167d82

Vinogradov, Y.B., Semenova, O.M., Vinogradova, T.A., 2011. An approach to the scaling problem 
in hydrological modelling: the deterministic modelling hydrological system. Hydrol. Process. $25,1055-1073$.

Wang, D., Tang, Y. 2014. A one parameter Budyko model for water balance captures emergent behavior in darwinian hydrologic models. Geophys. Res. Lett., 41, 4569-4577, doi:10.1002/2014GL060509.

Wang, D., Zhao, J., Tang, Y., Sivapalan, M., 2015. A thermodynamic interpretation of Budyko and L'vovich formulations of annual water balance: Proportionality Hypothesis and maximum entropy production, Water Resour. Res., 51, 3007-3016, doi:10.1002/2014WR016857

Wang, S., Fu, B. J., He, C. S., Sun, G., Gao, G. Y., 2011. A comparative analysis of forest cover and catchment water yield relationships in northern China. For. Ecol. Manage. 262, 11891198.

Wood, E.F., 1995. Scaling behavior of hydrological fluxes and variables: empirical studies using a hydrological model and remote sensing data. Hydrol. Process. 9, 331-346.

Zahabiyoun, B., Goodarzi, M.R., Bavani, A.R.M., Azamathulla, H.M., 2013. Assessment of climate change impact on the Gharesou River Basin Using SWAT hydrological model. Clean - Soil, Air, Water, 41, pp. 601-609, 10.1002/clen.201100652

Zhang, L., Dawes, W.R., Walker, G.R., 2001. Response of mean annual evapotranspiration to vegetation changes at catchment scale. Water Resour. Res. 37, 701-708.

Zhang, L., Potter, N., Hickel, K., Zhang, Y., Shao, Q., 2008. Water balance modeling over variable time scales based on the Budyko framework- Model development and testing. J. Hydrol. 360 (1), 117-131, 10.1016/j.jhydrol.2008.07.021 
Zhang $^{\mathrm{a}}$, X., Dong, Q.J. Zhang, Q., Yu, Y.G., 2020. A unified framework of water balance models for monthly, annual, and mean annual timescales. J. Hydrol. 589, 12586.

Zhang ${ }^{\mathrm{b}}$, S.L., Yang, Y.T., McVicar, T.R., Zhang, L., Yang, D.W., Li, X.Y., 2020. A proportionalitybased multi-scale catchment water balance model and its global verification. J. Hydrol. 582, $2020,124446$.

Zhao, J., Wang, D., Yang, H., Sivapalan, M., 2016. Unifying catchment water balance models for different time scales through the maximum entropy production principle, Water Resour. Res., 52, 7503-7512, doi:10.1002/2016WR018977

Zhou, G.Y., Wei, X.H., Chen, X.Z., Zhou, P. Liu, X.D., Xiao, Y., Sun, G., Scott, D.F., Zhou, S.Y.D., Han, L.S., Su, Y.X., 2015. Global pattern for the effect of climate and land cover on water yield. Nat. Commun. 6, 5918.

Zhou, P., Li, Q., Zhou, G.Y., Wei, X.H., Zhang, M.F., Liu, Z.Y., et al. 2008. Reply to 'Flawed assumptions compromise water yield assessment. Nat Commun 9, 4788. https://doi.org/10.1038/s41467-018-07065-5 
Figures

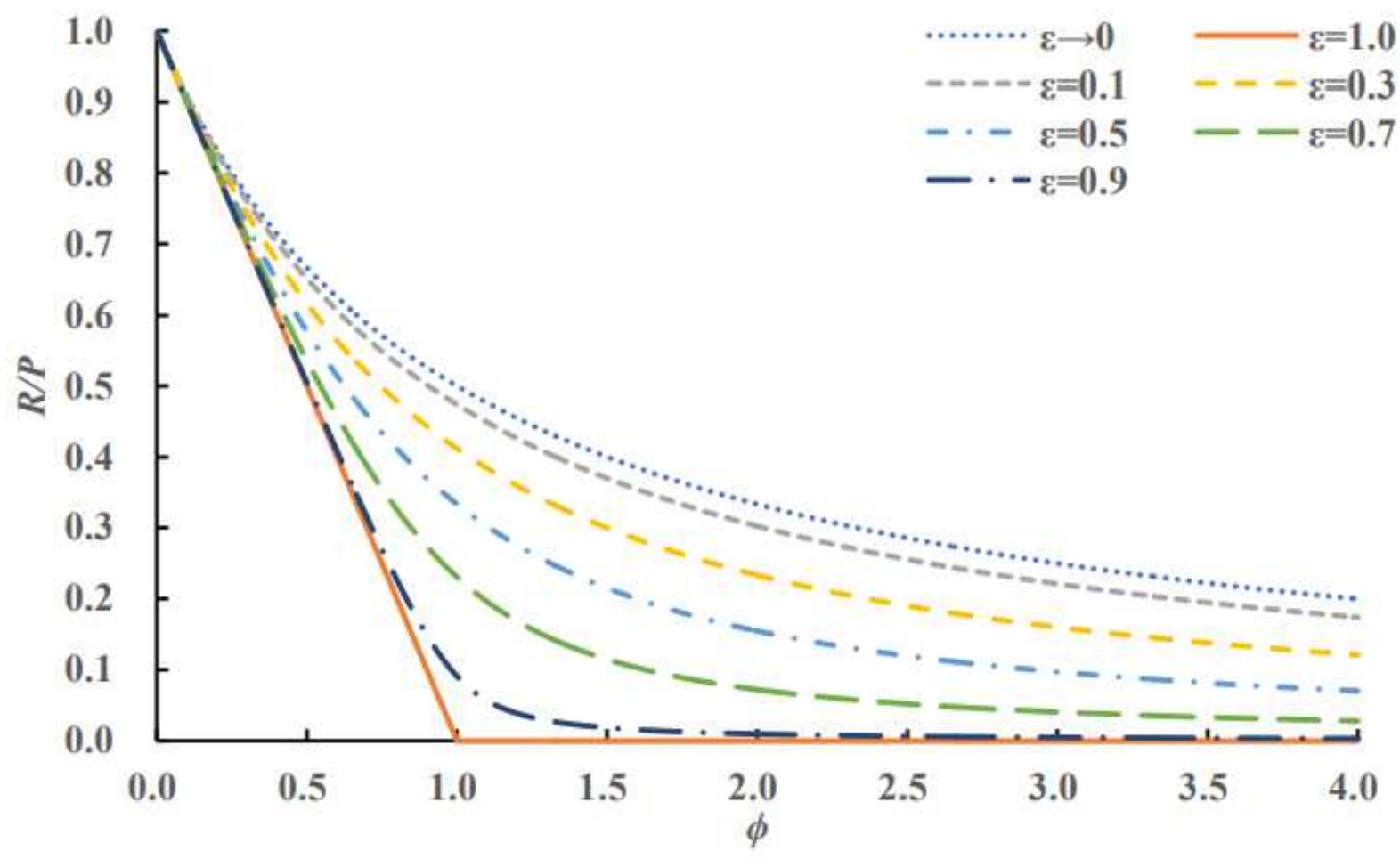

Figure 1

Ratio of Runoff to Precipitation (R/P) as a function of the index of the generalized dryness index $(\mathbb{\nabla})$ for different values of parameter $\varepsilon$ 

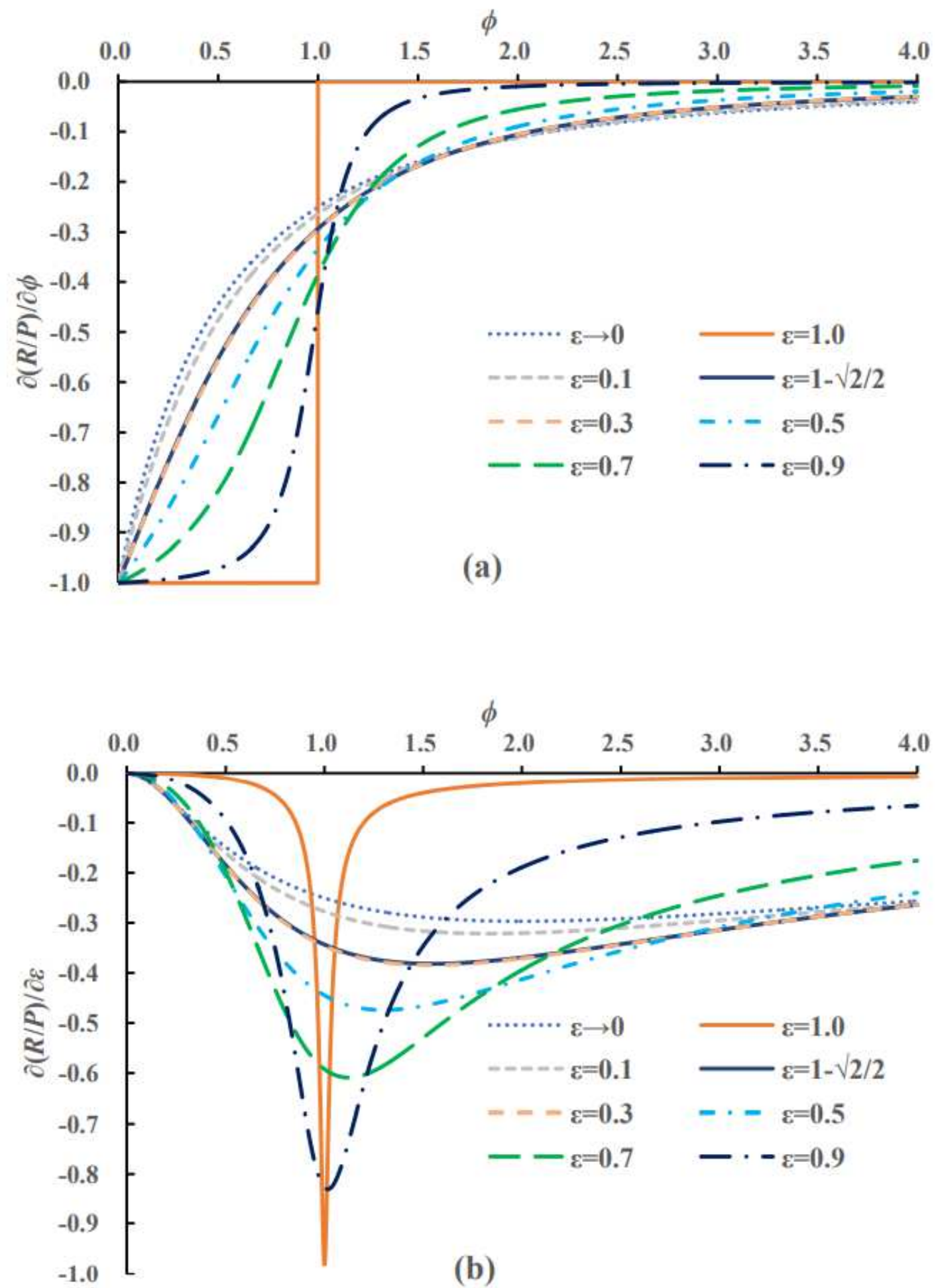

Figure 2

Distribution of the sensitivity functions: (a) R/P to $\nabla$ and (b) R/P to $\varepsilon$ 


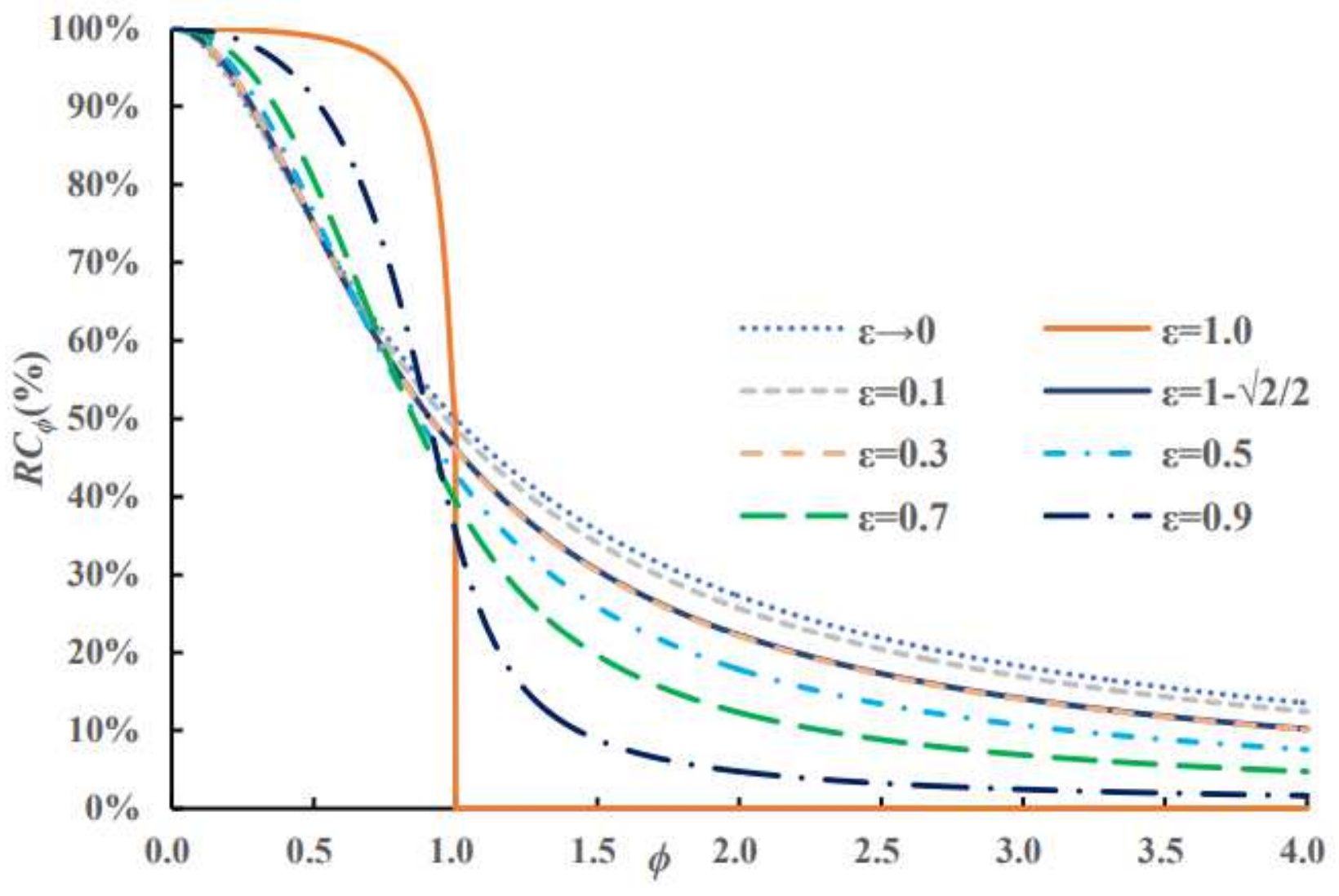

Figure 3

Relative contributions of $\nabla$ and $\varepsilon$ to water yield coefficient

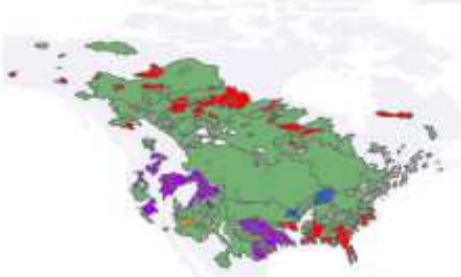

Forests

Shrublands

Savannas

Grasslands

Croplands

Mixed land

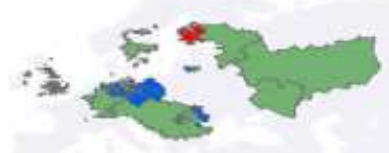

$\checkmark$
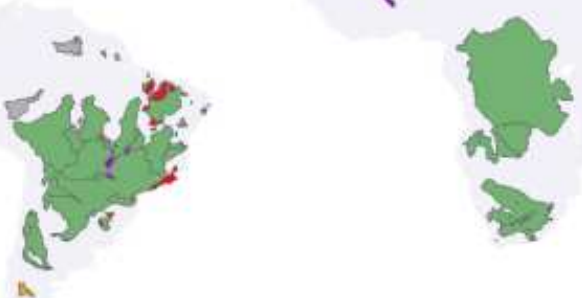
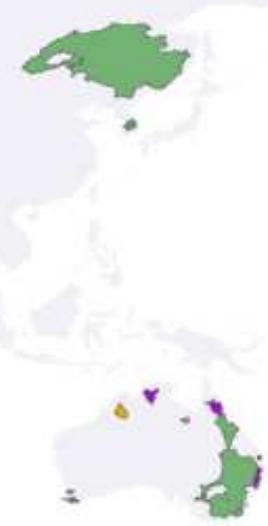
Figure 4

The selected basins and their land cover class

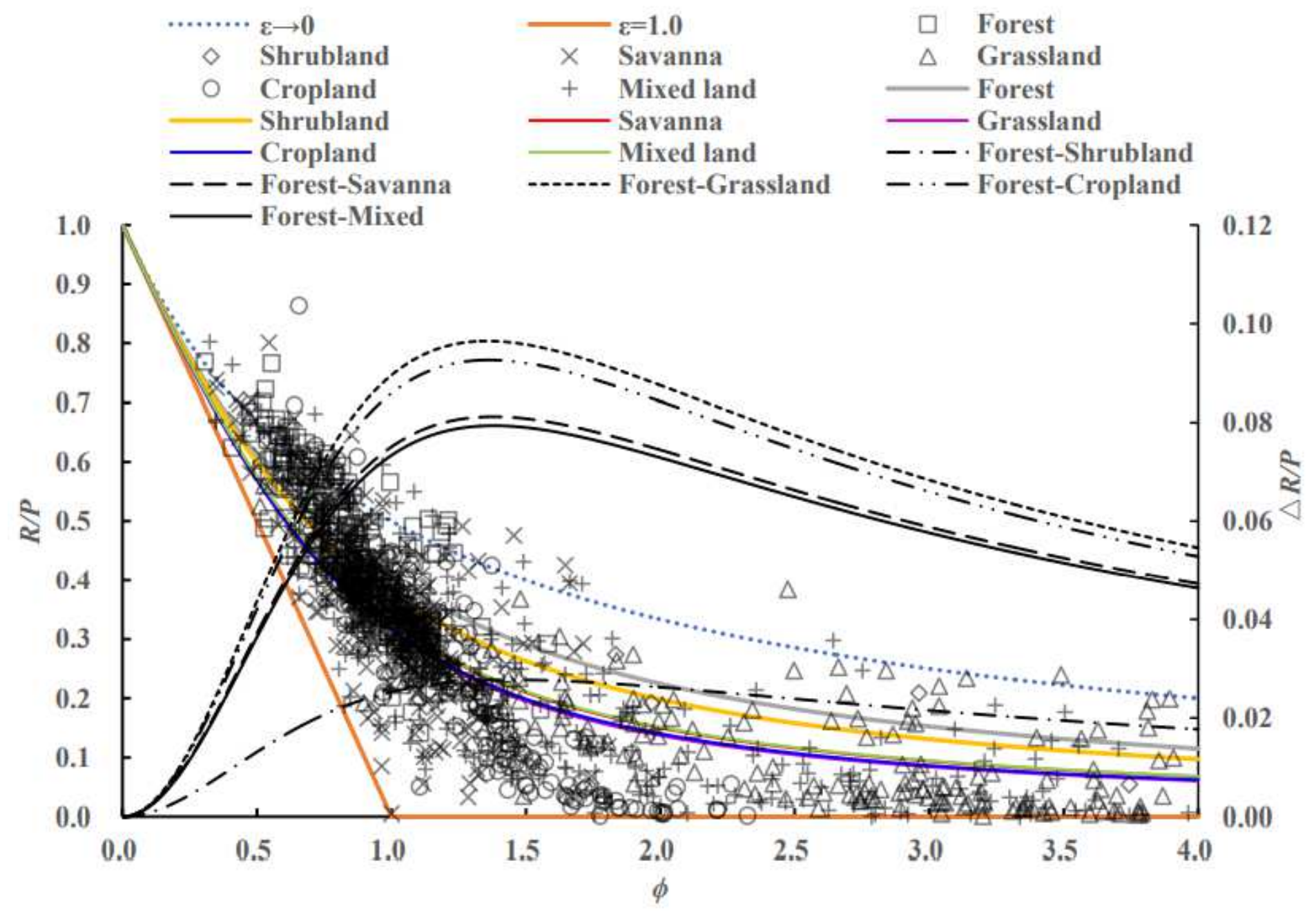

Figure 5

Validation of the water yield patterns at the annual scale 

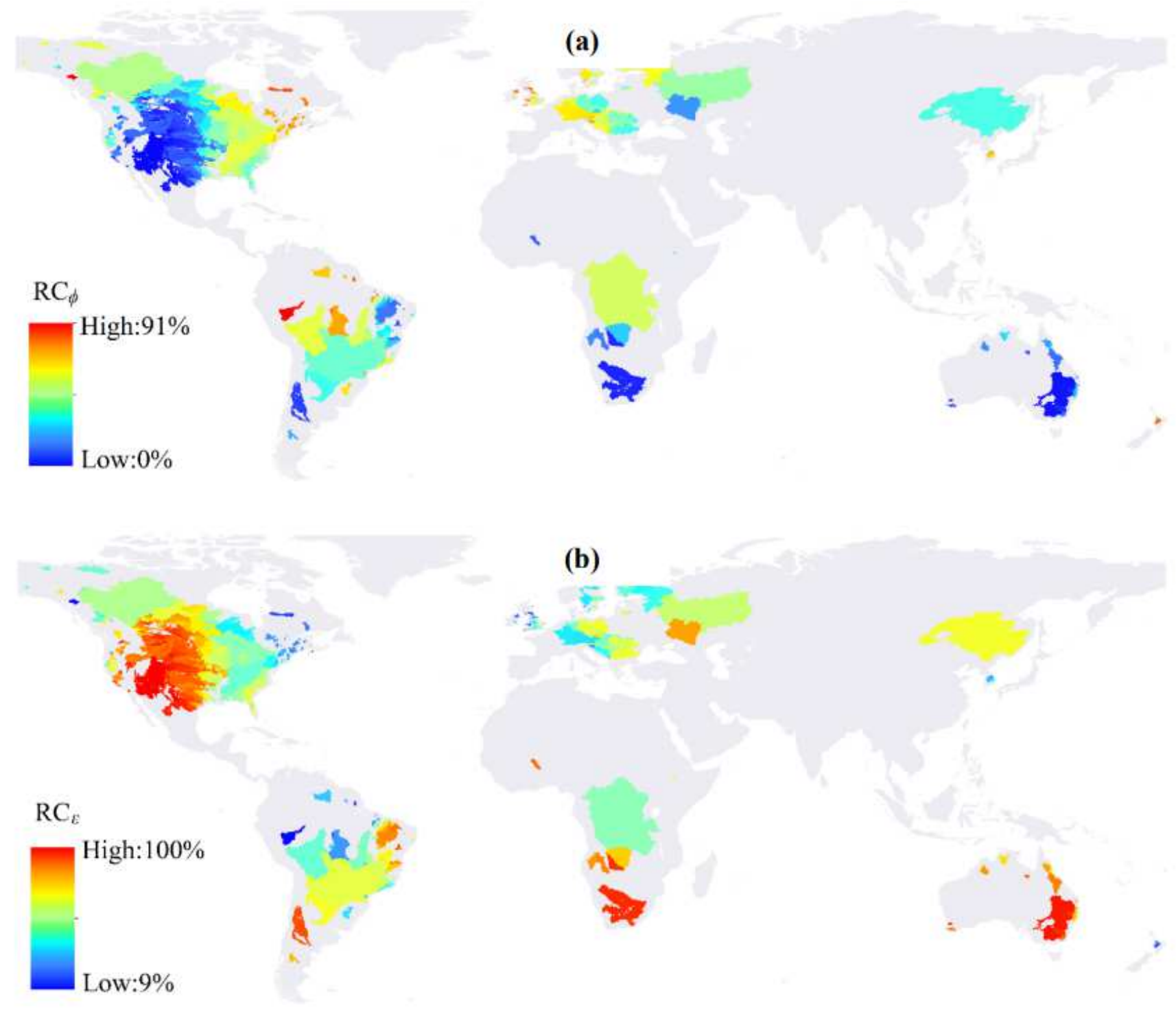

Figure 6

Global patterns for the contributions of: (a) $\nabla$ and (b) $\varepsilon$
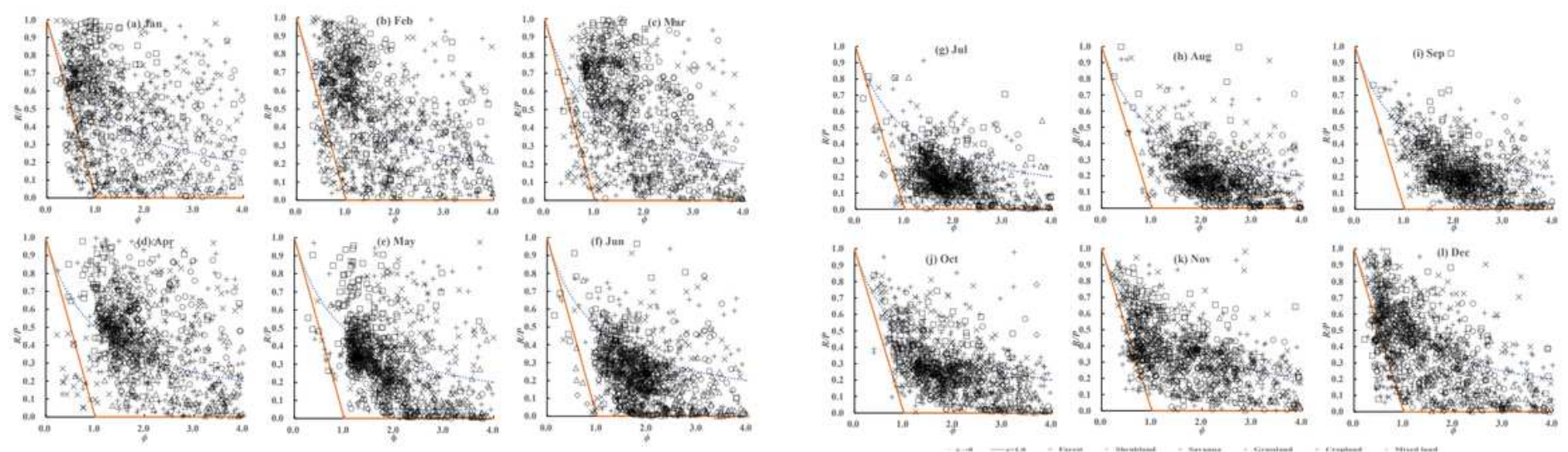
Figure 7

Validation of the water yield patterns at the monthly scale
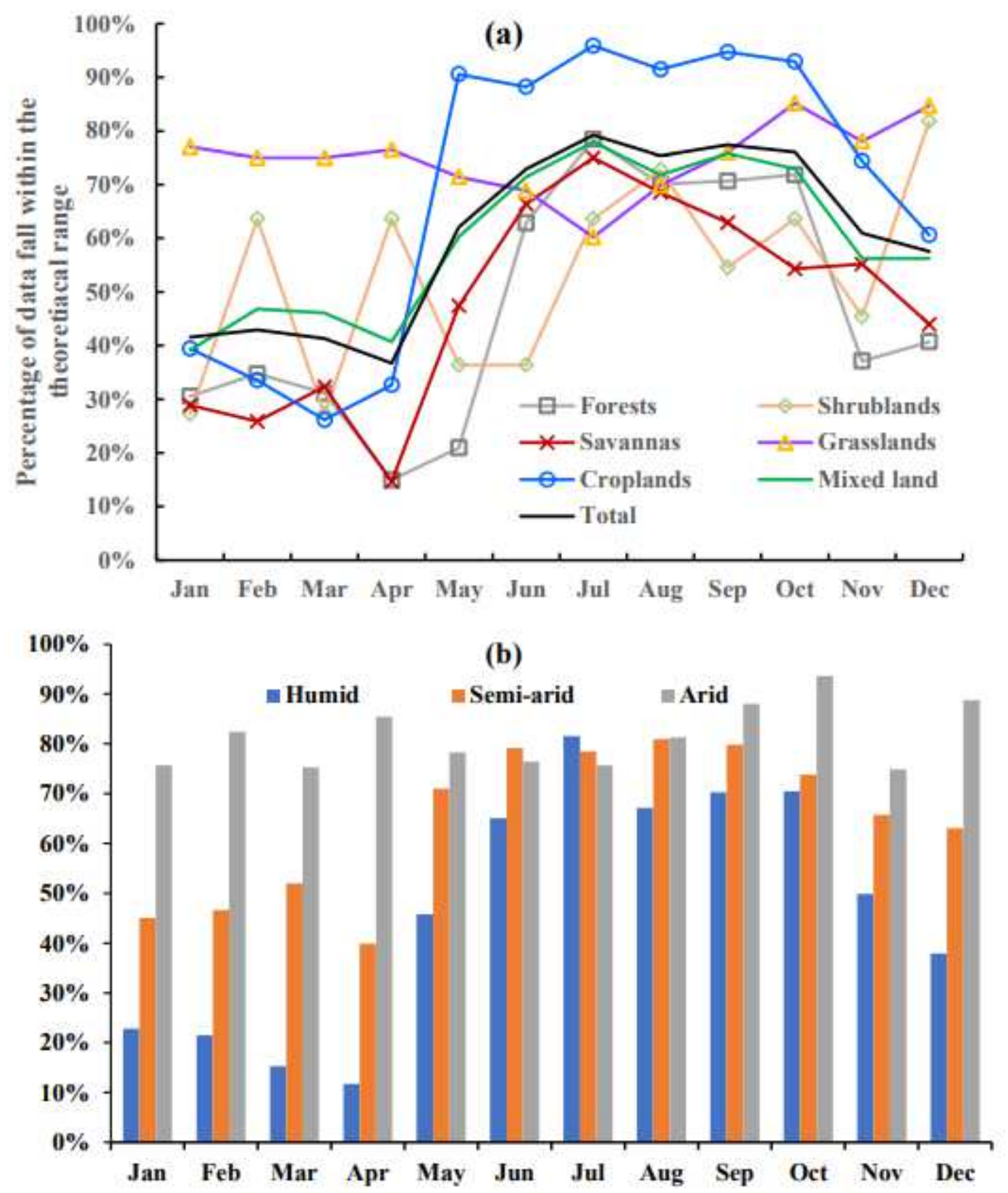

Figure 8

Percentage of selected data fall within the theoretical range at monthly time scale: (a) land cover; (b) climate zones 


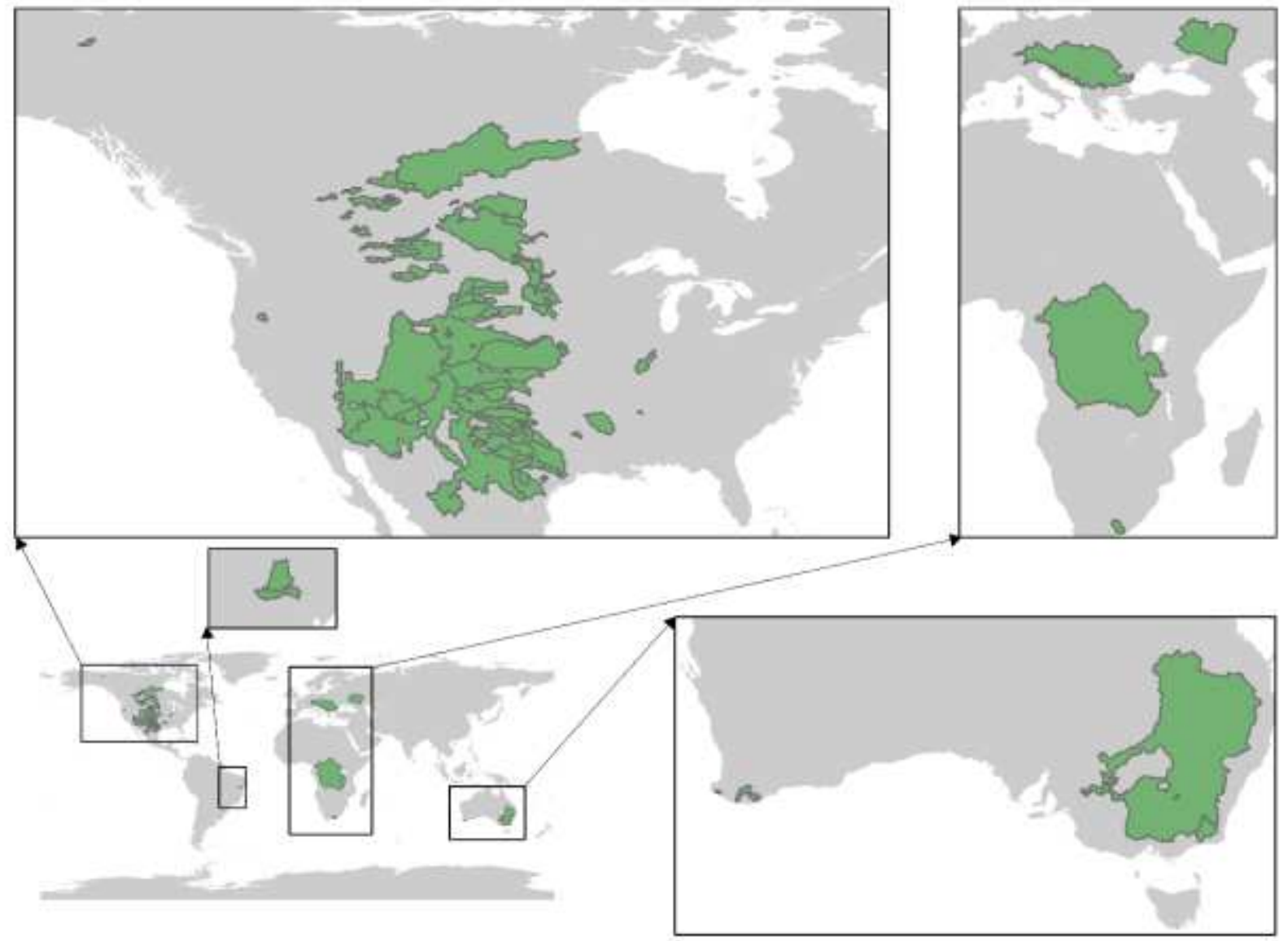

Figure 9

The selected 169 basins whose data set falling within the theoretical range for every month 


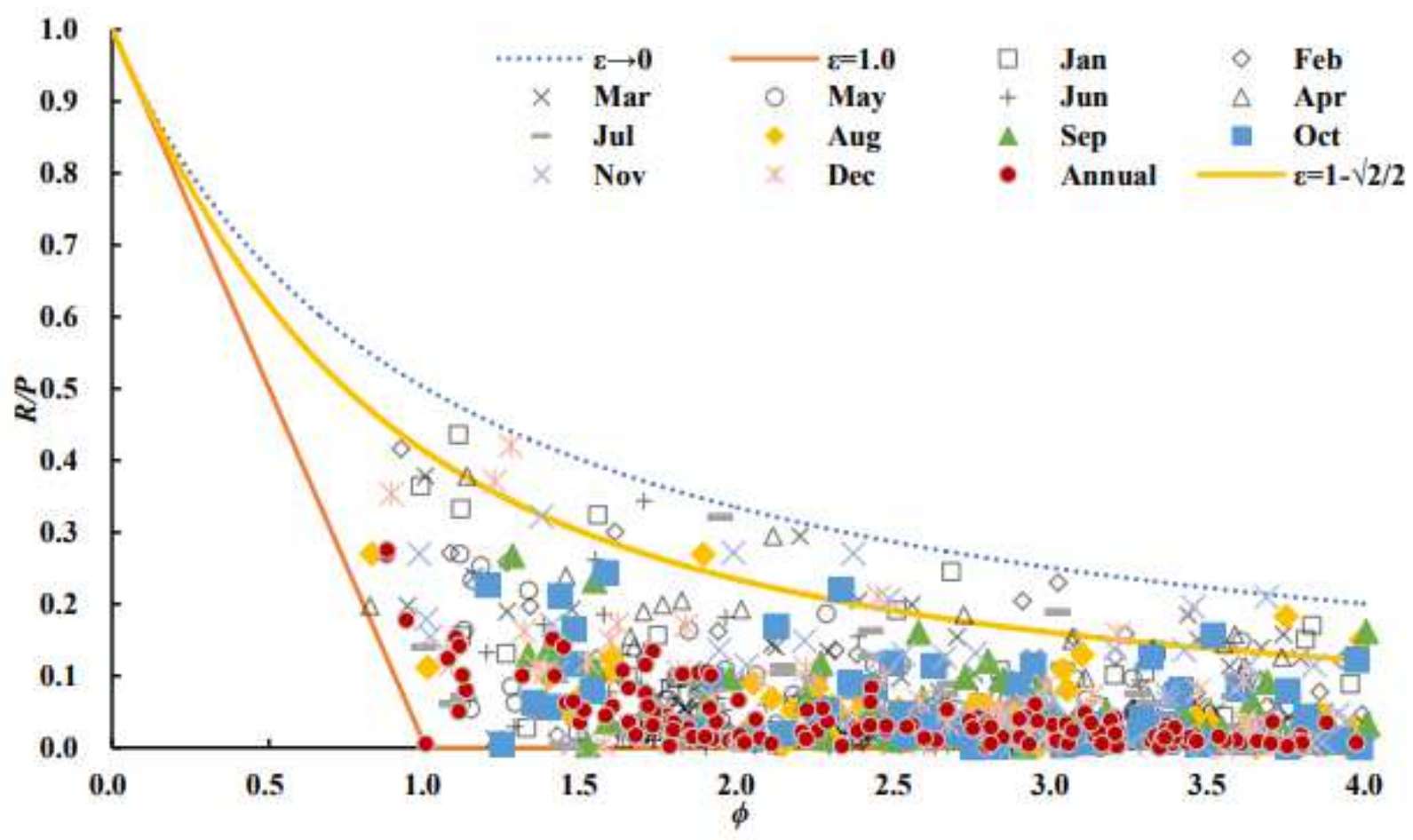

Figure 10

The water yield patterns at the annual and monthly scale for the selected 169 basins 
(a)

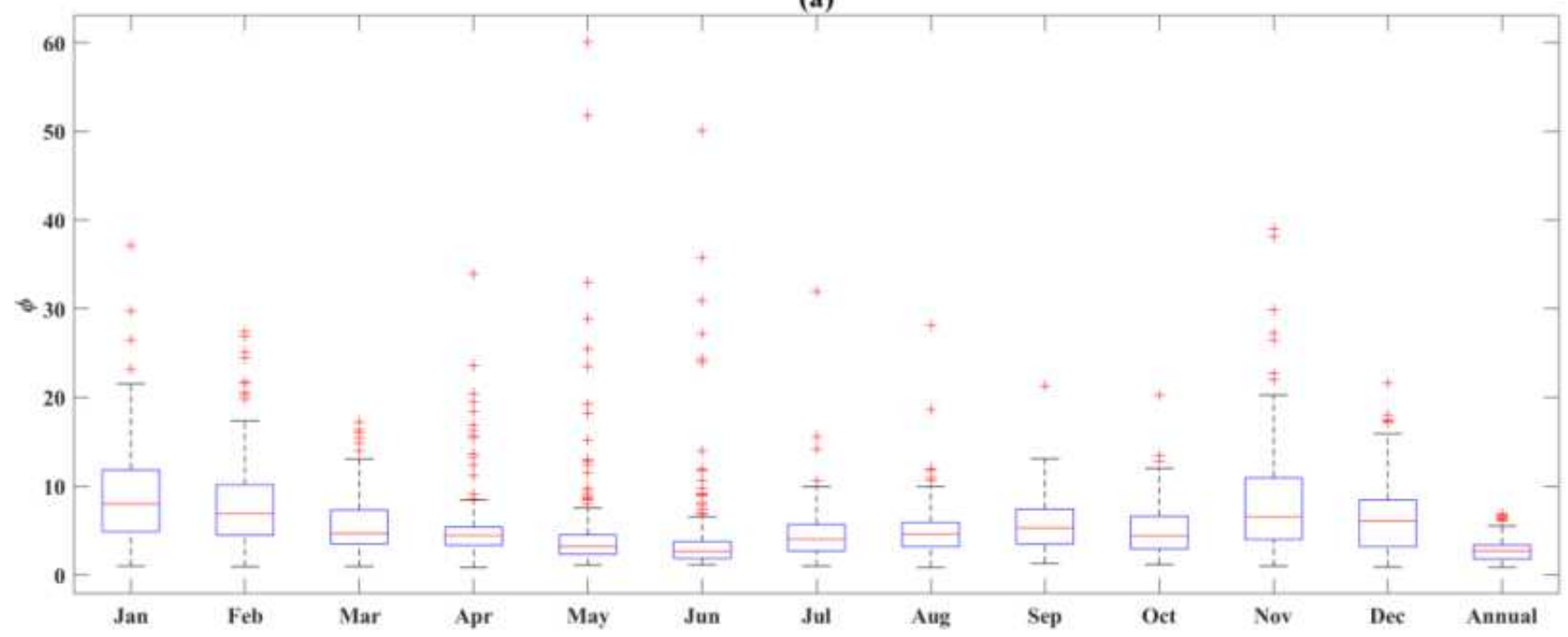

(b)

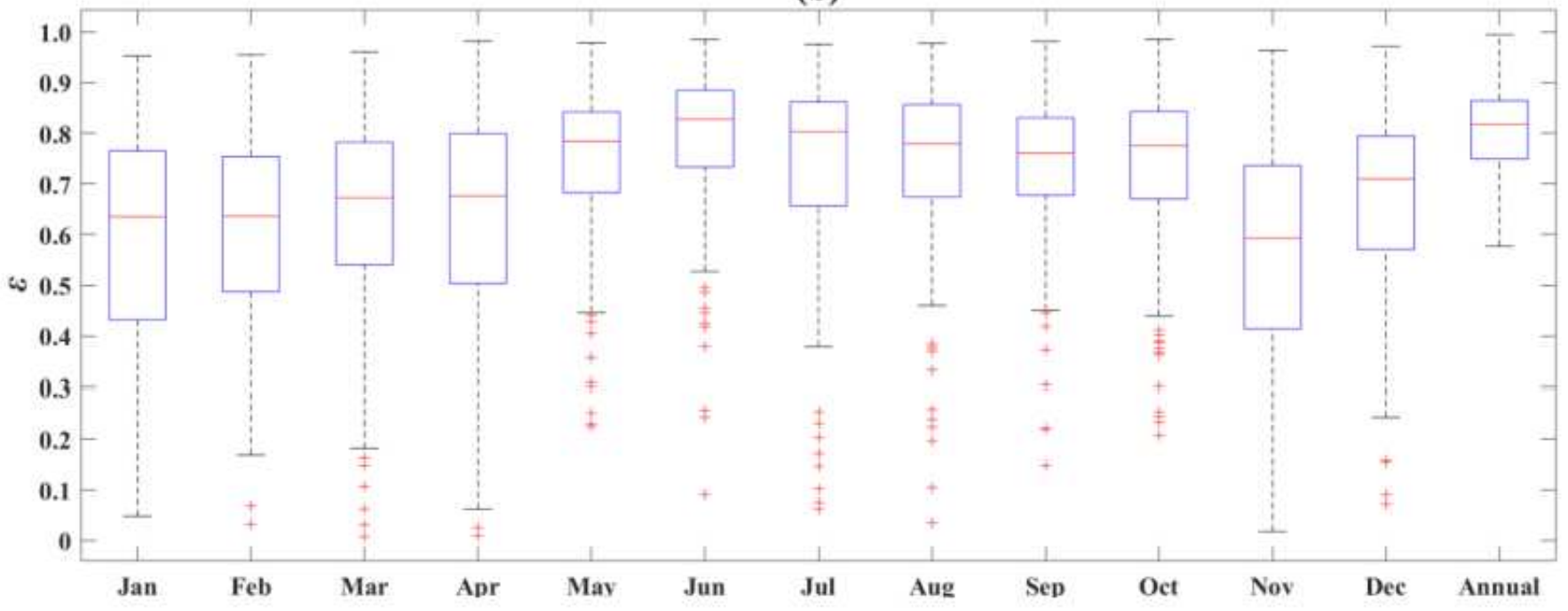

Figure 11

The annual and monthly values of $\nabla$ and $\varepsilon$ in the selected 169 basins: (a) $\nabla$ and (b) 


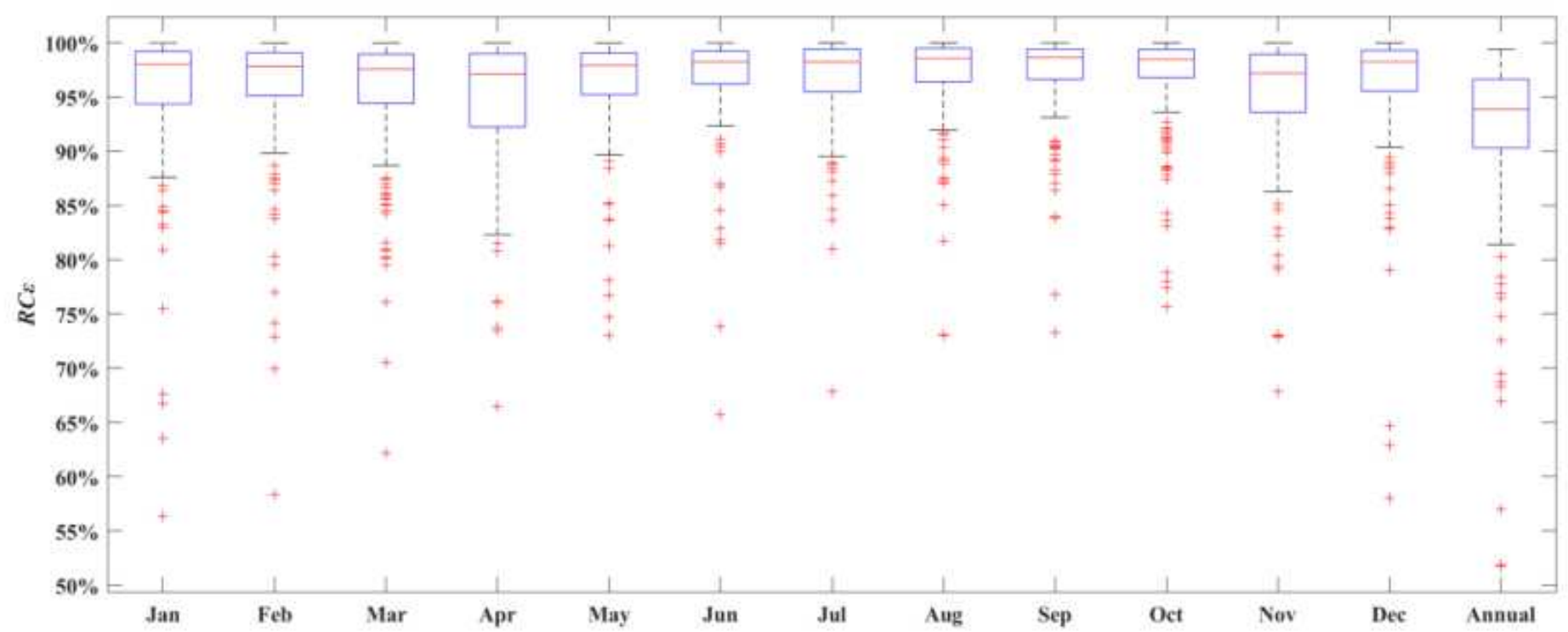

Figure 12

The relative contributions of $\varepsilon$ for the R/P for the selected 169 basins at monthly scale

\section{Figure 13}

The relationship between annual and monthly time scales: (a1) is for $\nabla$ while (a2) is for $\varepsilon$; (b1) is for

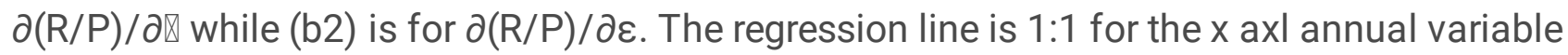

